\title{
Adjustment Experiences of International Graduate Students to Life in the United States
}

\author{
Nur Aira Abd Rahim \\ Department of Professional Development \& Continuing Education, Faculty of Educational Studies, Universiti \\ Putra Malaysia (UPM), 43400 UPM Serdang, Selangor, Malaysia
}

\begin{abstract}
The adjustment process, also interchangeably referred as a transition or adaptation process, is a stage that every international student went through as part of their study abroad experiences. For international graduate students, their pursuit represents an important milestone in their self-development and personal growth. However, adjusting to a new educational and social environment can be challenging. During this important starting point of their academic journey, what are the key aspects that shaped the adjustment experiences of these international graduate students? This study explored the narratives of international graduate students of their adjustment process to academic life in the United States using the integrated acculturation framework using a naturalistic qualitative inquiry process. Participants' selection includes criterion sampling and maximum variation strategy to elect international students who were at least completing his or second semester in a current graduate program. In total, 9 participants were selected based upon different countries of origins and program majors and having both male and female and doctorate and master level participants in this study. The findings show that these international graduate students experienced varied adjustment experiences, impacted by motivation, personality, coping strategies, and social support received. All the participants also reported having a varying set of growth as a result of the adjustment process. The recommendations include providing more support geared towards academic well-being and creating a supportive culture among faculty and other students on the diversity and difference these international graduate

ARTICLE INFO

students bring on campus.
\end{abstract}

Article history:

Received: 09 February 2021

Accepted: 27 July 2021

Published: 03 December 2021

DOI: https://doi.org/10.47836/pjssh.29.4.08

E-mail address:

nuraira@upm.edu.my

ISSN: 0128-7702

e-ISSN: 2231-8534
Keywords: Adaptation, adjustment, graduate students, higher education, international students, students' development 


\section{INTRODUCTION}

Cross-cultural adaptation is a long-term process of adjusting and finally feeling comfortable in a new environment (Hall, 2005). Cross-cultural means crossing cultures between two or more cultures. Kim (2001) reports that the phenomenon of cross-cultural adaptations has been widely investigated since the beginning of the 20th century. Every year, there are great numbers of groups and people who move across cultural boundaries. It includes long-term migration groups such as immigrants and refugees. People also move temporarily under various arrangements and purposes like employment opportunities, job attachments, and assuming roles such as diplomats and government agency employees, researchers, visiting professors, military personnel on foreign duties, missionaries carrying out religious service, summer study abroad students, and students seeking a degree in another country. They are also called the sojourners, referring to individuals who travel abroad to attain a particular goal within a specific period (Bocher, 2006). Foreign or international students are a prominent group that belongs to the sojourners' category. Their primary purpose is to study and obtain professional qualifications within a range of time from several months to several years if they attend a university.

Every year, many international students leave their home country to go abroad to pursue formal education. Many seek this opportunity to gain degrees in prestigious higher education, with longstanding motives either to acquire what international students generally perceive as a better education (Mazzarol \& Soutar, 2002) or possibly to increase their chances of professional prospects in their host country once they graduate (Trice \& Yoo, 2007). One of the top chosen countries for these purposes is the United States. The United States has one of the highest numbers of international students in the world. According to the 2020 Open Doors Report, the number of international students in the U.S in the 2019/2020 academic year was almost 1.1 million students across U.S higher education institutions (Institute of International Education, 2020).

International students contribute to U.S. higher education in various aspects, including educational, cultural, and financial aspects. The majority of international students are self-funded and support their studies through personal and family funds. It was estimated that international students contributed almost \$38.7 billion and supported 415,996 jobs to the U.S. economy during the 20192020 academic year (NAFSA, 2020). Living expenses largely contribute to their economic contribution for themselves and accompanying dependents, and through expenditures on out-of-state tuition fees, books, fees, and other education-related expenses.

Considering the significant number and large contribution of the international student population to the host country, many educators, especially those in the higher education field, have been dedicating their interests and time to studying this 
population. Therefore, the adjustment process, also referred to as the transition or adaptation process interchangeably is an integral stage for every international student who travels abroad for new educational experiences. However, adjusting to a new educational and social environment can be a challenging process. Considering the cultural differences and misunderstandings of the new and diverse experiences, it is likely that international students will experience feelings of estrangement, anxiety, and depression as a part of their adjustment process (Adler, 1975). In particular, the stress would be most prominent during the initial stage of the adjustment process (Hotta \& Ting-Toomey, 2013).

\section{International Graduate Students' Challenges in Cross-Cultural Settings}

For international graduate students, besides being international, they are also transitioning to graduate education, which offers different challenges altogether. Studies have shown that many students perceived difficulty transitioning to doctoral education, mainly becoming independent researchers (Gardner, 2008; Lovitts, 2005). A literature review study conducted by Gao (2021) highlights five international doctoral students' experience domains. The first one is the academic domain, which includes the relationship with the supervisor(s), peer and faculty support, and research challenges. The social domain focuses on family/spousal support and social networking, whereas the cultural domain includes language barriers and cultural adaptation. Meanwhile, two more domains are the psychological domain which identity issues and emotions, and the economic domain, which focuses on financial constraints. According to Gao (2021), these five domains shaped the whole experiences of international doctoral students and mutually influenced their overall cross-cultural experiences.

Gao's (2021) literature review highlights the two most frequent challenges faced by Doctoral international students. The first one is the student's relationship with their supervisor. Supervisors play a very influential role in doctoral students' academic lives. Doctoral students often reported struggles coming from imbalanced power dynamics, pressure, and misaligned expectations in various academic tasks such as research. Meanwhile, language barriers were found to undermine the students' overall experiences in their host country because they affected their communication with supervisors and peers, as well as their ability to undertake academic tasks and develop social networking. It was reported that lack of proficiency in English and different speaking English styles are major stressor that hinders the effectiveness of many international students in their studies (Ahrari et al., 2019; Faiz et al., 2017).

However, issues and challenges alone do not paint the overall picture of the crosscultural journey as experienced by these international students. Wang (2009) asserts that international students differ greatly in adjusting to their circumstances and studies. Some adjust easily, while others find it very difficult. For example, Bui (2021) provided 
insight into her intercultural experiences as a doctoral student and described it as a negotiated process between several cultural dichotomies. She reported negotiating several cultural differences, such as adapting from passive to active learners, accepting versus rejection, and transitioning between dependent and independent. In entirety, she also viewed the process as becoming an interculturally competent individual, indicating growth and learning process resulting from the whole Doctoral journey.

Acculturation is a complex process that is not linear (Birman, 1994). According to Berry (1997), varying factors should be considered when carrying out studies on cross-cultural adjustment. In his framework, Berry emphasizes the need for a fairly comprehensive review of variables concerning the group and individual levels, taking into consideration factors such as country of origin and settlement at group level, as well as various moderating and mediating variables at individual levels. Therefore, Berry $(1990,1992)$ suggested that each individual's acculturation or adjustment process is unique. Their individual experiences are assumed to be shaped by various factors before and during the adjustment process and may lead to different outcomes or changes after the adjustment process. It is the stance which this study wishes to undertake, to explore and present a more holistic representation of adjustment experiences from the perspectives of international students graduate.

\section{Purpose of Study}

The study aimed to explore the adjustment experiences of international students to life in the United States. This study used a naturalistic qualitative inquiry process to empower the narratives as told by these selected individuals to capture the complexity of the international graduate students' adjustment process. In its broadest sense, narrative refers to any spoken or written presentation (Schwandt, 2007) or as prosaic discourse (Polkinghorne, 1995), elicited from selected individuals with personal experiences and stories to share about the phenomenon of interest. In specificity, this study was interested in exploring the adjustment experiences of international graduate students, as guided by the following three research questions:

1. What are the experiences encountered by international graduate students during their adjustment process of life in the United States?

2. How do international graduate students facilitate their adjustment process?

3. How do international graduate students change as a result of the adjustment process?

\section{Adjustment Process in Cross-Cultural Experiences and Related Terms}

There is a broad literature that governs the field of cross-cultural studies. In examining the process of adjustment in a cross-cultural context, literature has reported various terms used in previous studies, such as 
transition, adaptation, acculturation, and interculturation. According to Kim (2001), the word adaptation employs the definition that follows the open-systems perspective of organisms or groups of organisms' responsive change to environmental demand. Thus, adaptation refers to a more inclusive overarching process of crosscultural change, defined as the dynamic process by which individuals, relocate to new, unfamiliar, or changing cultural environments (Kim, 2001). Meanwhile, major usage of the term acculturation can be found in Berry's $(1990,1997)$ works. According to him, the concept of acculturation refers to the cultural changes resulting from new group encounters. In Berry's (1992) perspective, adaptation is the term used to refer to both the process that happened during acculturation and its outcome. Finally, the term adjustment, or adjusting, refers to the strategy most often used during adaptation. Changes in the individual are initiated to reduce conflict and increases the congruence or fit with the new environment.

Interculturation is another related concept discovered in French literature with a parallel meaning to acculturation. The concept is defined as "the set of processes by which individuals and groups interact when they identify themselves as culturally distinct" (Sam, 2006). Hall (2005) synthesizes the work of many authors and refers to acculturation as the cultural and psychological change brought about due to contact with peoples of different cultures. Most recently, Garcia et al. (2020) expanded the construct of the acculturation model to include multiple levels of interaction between psychological, instrumental, contextual, and developmental aspects to form the Integrated Acculturation Model.

\section{Underpinning Theoretical Framework}

This study used the Integrated Acculturation Model (AIM) (Garcia et al., 2020) as the underpinning theory. The AIM model integrates the interactions of four perspectives to explain the acculturation process; from the psychological, instrumental, contextual, and developmental perspectives. For a visual representation of the AIM model, please refer to Figure 1. The psychological perspective explains the affective and cognitive components in the identity development of crosscultural individuals. This perspective includes seeking or strategizing to achieve a sense of belonging, affirming, developing allegiance, or developing a feeling of salience when forming a new identity during the interculturation process. Meanwhile, the instrumental aspect of acculturation refers to how an individual can perform effectively within each cultural identity, in which acculturation strategies will manifest. The AIM model also takes into account the dynamics of contextual factors in the acculturation process. This contextual perspective can be examined from conceptual factors such as perceived similarity of the origin and host culture and societal climate of the host country. Contextual perspective also consider the domain factors, referring to important life 
contexts in which acculturation occurs, such as the individual's linguistic, education, work, family, politics/civics, spirituality/ religion, values, and social background. The contextual perspective also factor in the process in which the acculturation takes place, comparing the notion between individual and group acculturation, as well as the process for adjusting for permanent or less permanent cultural contact. The fourth perspective of the AIM model is on the development dynamics of the acculturation process. This perspective views acculturation as a non-static process, therefore with continuous exposure to new ways of being, an individual will maintain or amend their cultural expectations and practices. The developmental perspective states that the result of one acculturation process provides the foundation for the beginning of the next, indicating changes and growth over the acculturation or adjustment process as a whole. Using a naturalistic qualitative inquiry process, this study broadly explored the perspectives described in the AIM's model in examining the adjustment process of international graduate students in the U.S. The following section expands the methodology used to conduct this study.

\section{METHOD}

\section{Design of the Study}

Qualitative research is a type of inquiry that encompasses several philosophical orientations and approaches (Merriam, 2009). It stresses the socially constructed nature of reality, the intimate relationship between the researcher and what is studied, and the situational constraints that shaped the inquiry (Denzin \& Lincoln, 1994). This study employed a naturalistic qualitative inquiry process to elicit the narratives as

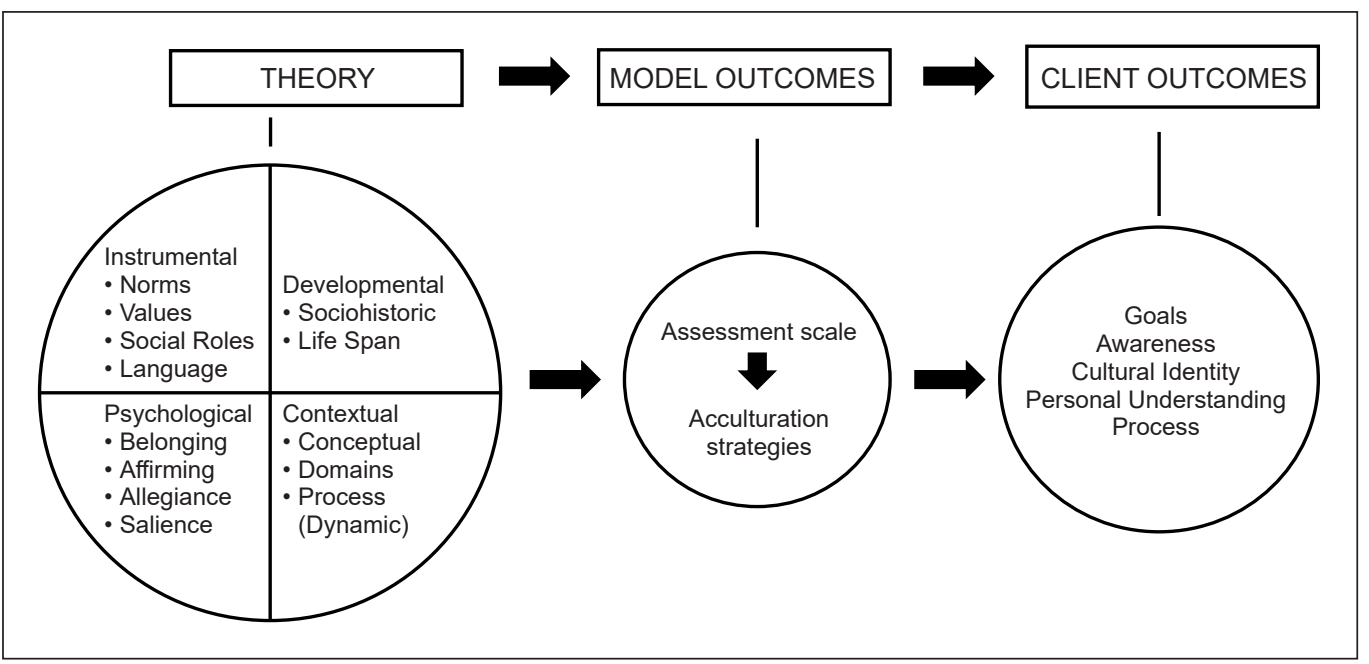

Figure 1. The Integrated Acculturation Model (AIM)

Note. This is the Integrated Acculturation Model (AIM) proposed by Garcia et al. (2020), illustrating the interactions of four perspectives to explain the acculturation process; from the psychological, instrumental, contextual, and developmental perspectives. 
told by these individuals to gain insights into how international graduate students socially construct their experiences of cross-cultural adjustment. This approach was selected based on the argument that Clandinin and Connelly (2000, p. 18) posit; "Narrative is the best way of representing and understanding experience. Experience is what we study, and we study it narratively because narrative thinking is a key form of experience and a keyway of writing and thinking about it". By studying the events as they unfold through those who live, we can gain insight into what international students know and how they know and believe are altered or shaped through their experience (Harris, 2003). The storytelling process (Connelly \& Clandinin, 1990) was adapted as a data collection strategy to capture the narratives of the adjustment process, as experienced by these international graduate students.

In identifying the study participants, this study used nonprobability sampling since generalization in a statistical sense is not a goal of qualitative research. On behalf of the researcher, an invitation to participate in this study was sent out via email to the mailing list by an international service officer. The email was linked to an electronic flyer describing the study, eligibility criteria for participation, participation compensation, and the researcher's contact information. Criterion sampling strategy (Miles \& Huberman, 1994) was used to select participants with the most relevant experiences, including an international student who was at least completing his semester or second semester in a current graduate program at a selected Southwestern university in the U.S. Although 12 international students volunteered to take part in this study, 3 participants had to be excluded because they were cultural exchange students who only stayed in the country for six months. Participants were also recruited using a maximum variation strategy (Patton, 2002) to attain a diverse representation sample of international graduate students. In total, 9 participants were selected based upon different countries of origins and program majors, as well as having both male and female and doctorate and master level participants in this study.

Data were primarily collected via semistructured interviews. In semi-structured format, although the questions were set beforehand, they are less structured, more flexibly worded, and do not have to be asked in certain orders (Merriam, 2009). It allows room for the researcher to be responsive to the individual's responses during the interview. In addition, a method called photo-elicitation (Merriam, 2009) was employed to enrich the data collected during the interviews. Photo elicitation is based on the simple idea of inserting a photograph into a research interview (Harper, 2002). Photo elicitation interviews can enhance the qualitative method and help address some pitfalls in conventional interviews. This method also helped ease rapport between researcher and interview, provide structure for interviews, lessen some of the awkwardness of interviews and help researchers interact better with 
people they are studying (Clark-Ibanez, 2004). Participants were shown a set of 12 cards that contained various graphics and were asked to choose two cards that best represented them. Discussion followed on how the participants relate themselves to their selected cards, which led to more stories shared by the participants during the adjustment process.

Using an exploratory lens, data were thematically analyzed through the initial open coding process, followed by categories construction and organization of the stories into themes to interpret the larger meaning of the experiences and stories shared by the participants. Finally, to enhance the validity and reliability of this study, a member's check process and data triangulation were conducted, leading to the findings.

\section{FINDINGS}

The findings of this study were categorized into three key themes. The first theme discussed the mosaic nature of the adjustment experiences as shared by the participants. The second theme elaborated on the strategies used by the international graduate students to facilitate their adjustment process. The third theme presented the learning growth experiences as discussed by the participants as a result of their adjustment process. The emerged themes were also analyzed compared to the AIM perspectives for identifying the corresponding elements in the adjustment process reported by the participants against the acculturation framework used in this study. All their names were changed and referenced generically in the following findings to protect all the participants' confidentiality and anonymity.

\section{Theme 1: The Mosaic Nature of Adjustment Experiences}

The first theme reported on the mosaic nature of the participants' adjustment experiences, including the varying degrees of feelings reported during the process. For most of them, being in the United States was the farthest they have ever been from home, and for some, it was their first time being abroad altogether from their home country. Overall, their narratives can be divided into two subcategories, (1) psychological experiences and (2) sociocultural experiences. These two sets of emerged narratives are consistent with the two perspectives outlined by the AIM model, referring to the psychological and contextual perspectives of understanding the acculturation process (Garcia et al., 2020). Psychological experiences focus on the emotional and affective reactions that the participants had described their adjustment process. Feeling homesick, anxious, and experiencing culture shock was reported, in varying degrees, in which some participants experienced it longer and intense than the others. For most of them, the feelings were intense during the first few weeks, and for some, up to several months from their first day of arrival to the U.S. One participant illustrated how he felt:

Actually, I arrived at night so I couldn't see around much, but I liked the way the airport was operated. 
But the next morning, when I woke up, it was all empty, all over, which was pretty unfamiliar to me, no pedestrian at all as opposed to Dhaka (capital city of Bangladesh)! So yes, like the streets, I felt very empty inside. I felt like, why I came here, leaving my friends and family (behind). (Bangladeshi Student 1)

A similar theme was echoed by another participant, who compared her life in her hometown to her new surroundings here in the U.S.

I mean the life in the U.S. is really not great, not as colorful as my life in China. I have lots of friends in China, we can have lots of fun, but here's very different. I mean, right now is kind of okay. But when I first came (to the U.S.), it was really not okay. (Chinese Student 1)

Interestingly, for one participant, although it was not her first time in the U.S., moving to yet another new city here in the U.S. triggered the homesick feeling that she did not experience when she first moved to the U.S. from Korea. She noted the unfamiliarity of everything all over again, which caused her to feel homesick, even after years of living in the U.S. previously. She said, "Actually when I came here, Ifelt homesick. As if it's my first time here (in the U.S.) After a couple of years, I'm surprise that it came to me. Like I never felt it before, but suddenly now.." (Korean Student 1). The feeling of homesick and loneliness was mainly attributed to a lack of familiarity with the surroundings or preferred cultural environment compared to what they are used to back in their hometown similar to what Sawir et al. (2008) described as cultural loneliness. Over time, however, the feelings subsided based on several factors, such as increased familiarity with new surroundings, shifted focus and attention to academic goals and processes, and accumulated cultural competence after being in the adjustment process over some time.

The participants also talked about their sociocultural experiences as part of the adjustment process. Adjusting to a new place made them especially observant of the differences between their home countries compared to their new surroundings. Because their migration purpose to the U.S was to attain a graduate degree and gain valuable academic experiences, the lives of participants in this study mostly revolved around their school environments and classes. Therefore, their sociocultural experiences during adjustment were primarily described based on their interactions with faculty members, academic advisers, classmates, and their learning experiences in classes. For example, academic culture difference has been identified as one of the key stressors among international students (Kingston \& Forland, 2008). Among the participants, there were reports of different expectations from the U.S. professors compared to how things were back in their home country. For example, one participant pointed out that the U.S. culture emphasizes more on learning than attaining good grades, which she perceived as opposite to the culture in her home country. She explained: 
I remember like I was really stressed out towards the end [of a chemistry class] because I thought I wasn't going to make an A. At that point, that was the most important thing for me, like getting an A. I was still a little kind of more worried about all the grades. Like here (in the U.S.), they seem more serious about learning, it's more about learning... You have to get at least a $B$ to pass, but as long as you get a $B$, it doesn't really matter, I mean, it matters, but for them, it's more like "did you learn something?" That was the main focus. (Korean Student 1)

Another participant shared about the differences he noted in the way exams were asked, as compared to the way he was used to back in his home country, "In India, they teach a little bit and then scope of the questions can be large, but not really in depth, but you have to look at a lot of things. That what it was there but here it was like, more of going in depth of the portions that are covered in class. I didn't know that" (Indian Student 1). For these international students, adapting to these different academic norms and expectations was also viewed as part of their adjustment process.

Interactions with peers and classmates were also discussed; some participants had an early opportunity to mingle with local Americans as their classmates, which was seen as an added advantage. Because sociocultural adjustment is geared toward linking individuals effectively into the new context, engaging in cultural learning became a required process. Culture learning is the effort to gain insight into how cultural strangers live (Hess, 1994). It requires individuals to be familiar with the new cultural values that include differences in language, nonverbal cues, rules and conventions, and norms and values (Masgoret \& Ward, 2006). However, not all participants reported having the same opportunity for constant intercultural contact; not everyone was comfortable initiating friendship with the locals during the initial adjustment process. Rather, it was a gradual process that was built into their sociocultural experiences over time.

The AIM underlines a similar interaction process during acculturation, highlighting the interplay of important life contexts, such as the individual's linguistic, education, work, family, politics/civics, spirituality/ religion, values, and social background, in which acculturation occurs (Garcia et al., 2020). In particular, the international graduate students' adjustment experiences were mostly built around their academic surroundings as the key starting point of their interculturation process.

\section{Theme 2: Multiple Strategies Used to Facilitate the Adjustment Process}

The second theme focused on finding out the strategies international graduate students use to facilitate their adjustment process. This theme is parallel to what the AIM refers to as the instrumental aspects of the acculturation process, referring to the manifestation of the acculturation strategies 
to ascertain the degree to which individuals can perform effectively in the new cultural setting (Garcia et al., 2020). Three coping strategies were identified; (1) shifting to positive mindsets, (2) concentration on academic-related matters, and (3) establishing key social supports. In the first strategy, participants reported how they realigned their expectations and mindsets to view their adjustment process positively. For example, one participant casually expressed, "The easiest way is to adjust your mindset and think positively. Don't think about it [the challenges] negatively, but more of, how can I learn from this? Positivity and all.." (Taiwanese Student 1). For these international students, shifting their locus of control from the external situations such as the hardship faced during adjustment to internal positive thoughts was seen as an empowering way to adapt to the adjustment.

\section{At first, I felt like it was overwhelming. Everything is just different. I'm always not sure, like don't know a lot of things. Even you know, as simple as like, buying grocery. But surprisingly, I did quite well on my first test. So I said, look, you can do it. I mean, graduate school is tough, but I did it. So new place, it should not be a problem. Soon, I was okay. Back to normal. Yay! (Taiwanese Student 1)}

As noted by Masgoret and Ward (2006), personal factors such as are internal motivation and self-expectations do affect an individual's cultural learning process; it contributes to the individual's intercultural competence, encompassing a behavior of understanding, satisfaction, and adaptation to function in a differing culture other than one's own.

Secondly, participants also discussed on how their sense of alienation during the adjustment period was mitigated by shifting their concentration on academicrelated matters. Their studies became their key motivation and distraction from the unpleasant feelings (such as homesickness and loneliness) during their adjustment period. One participant admitted that he found the adjustment process to be frustrating and difficult at first. However, he also thought his studies helped to distract him from thinking about the difficulty so much. He recalled,

I found it (the adjustment)
frustrating at first. Actually,
more than frustration, it was the
toughness of life here that at times
got me weary. But with so much
homework to do, I barely got a
chance to ponder over it, which was
good. (Bangladeshi Student 1 )

Because their migration purpose to the U.S. was for gaining academic credentials, these international students anchored their motivation and concentration towards fulfilling this purpose, even as early as during the first few weeks of their arrival. One student shared,

I came here two weeks before the semester started. Just to settle 
things down. I don't want to get lost and not have stuff before I start class. It's important to be able to focus on my study [after that]. The adjusting period was that two weeks. After that, it was all about the classes. Once I started to focus [on academics], I no longer think [about] adjusting. It's all just [about] studying. That's it! (Korean Student 2)

Another student spoke about how he kept himself busy with his study; "Once I started my coursework, I forget. Suddenly I'm not homesick at all, just busy, busy. I stick to my study schedule." (Indian Student 1). One Chinese student also resonated with the same strategy, "when I don't want to think about China, I will go to the lab or do my assignments. It can make me forget [about] being homesick for a while" (Chinese Student 1). Due to these compensating strategies, international students are often academically successful despite facing various social and academic issues during their adjustment (Andrade, 2006).

Coping with the adjustment process also did not happen in isolation. The third key strategy reported was on establishing strong social support. Social support is one of the moderating factors identified in Berry's (1997) acculturation framework. These participants regarded their interactions and socializing with friends and peers, directly and indirectly, helped them go through the adjustment process. Some perceived their friends directly helped during their adjustment because they received temporary housing, transportation, food, furniture, and utensils. While receiving physical assistance was helpful, this help also contributed to their psychological well-being during the adjustment. These students felt like they were being cared for during their time of need. As noted by one student, "I feel safe like, being less worried because I'm in good hands.." (Korean Student 2). Receiving psychological support was particularly important to ease and soften the experience of culture shock, defined as the process of initial adjustment to a completely unfamiliar environment (Pederson, 1995). Another student shared why such support was significant to her:
A friend I met here [helped me] she's from China. During my first time, she invited me home, and she cooked for me, and then, we became very good friends until now. She's very kind and makes me very comfortable and makes me feel, yeah, I have a friend here.... (Chinese Student 1)

Because the adjustment process was also associated with changes in the sociocultural environment, having frequent interactions with peers and friends was also indirectly perceived as an important strategy during adjustment. The social interactions ease the cultural loneliness or cultural distance these new international students face. One student shared,

Surround yourself with high-energy people...I'm surrounded by many 
friends who stimulate me, like study more, or so, surrounded myself with high energy people is very important because it focuses on my study and focus on my purpose and so, I think through the transition, it's very important to be friends like that. (Japanese Student 1)

Making friends with the local students became a focal strategy when these international students wanted to bridge their cultural distance and improve their language competencies. They perceived that the opportunity to make friends with local Americans usually helped them assimilate better with the local culture. Interactions acquired through informal social gatherings such as "learning about [name of the city] like the locals" or "picking up the American accent here and there" (Chinese Student 2) resulted in increased familiarization of the new surrounding and cultural-linguistic; thus, making these students feel more belonged and less alienated in the new country. Meanwhile, maintaining social engagement with fellow citizens was also deemed helpful from different aspects; in terms of sharing information or resources, and maintaining common connection and cultural familiarity. One participant said, "Most of the students in our lab are from China. So, it's good, we are all from China so we have the same experience as the college or something, and we can also interact using Chinese language" (Chinese Student 1).

\section{Theme 3: Experiencing Learning Growth during Adjustment}

According to Kim (2001), adjustment is not just about changing oneself to fit the new environment, but the process also offers many opportunities for new learning and growth. Experiencing learning growth resulting from the adjustment process was a consistent theme among all the study participants. Their reported growth can be divided into two; personal and interpersonal growth.

Personal growth refers to the internal growth of the individuals, either in knowledge, affective, or skills. For example, one student profoundly shared, "I think overall, all the aspects of me have changed for good" (Indian Student 1). He shared how he noticed a significant improvement in his confidence, communication skills, and time management. He even associated the improvement as indirectly contributing to his academic skills because:

Some of these, it's like life survival skills, you know, it's just as useful to apply even in grad school. Like I don't own a car here, I need to wait for the bus every day, so I learned the value of time [management]. I created a schedule for everything, including my study. It simply works together, which is awesome. (Indian Student 1)

Because these students anchored their coping strategies by shifting their focus and attention to their studies, they found the efforts were paid off not only in 
their adjustment but improvement in their academic focus and skills as a whole.

Night-time for me is the most lonely [period]. Not like China. Over there, I used to go out with friends. But here, I don't have transport. So that's why I have more time to read the materials given by a teacher. Now I think it's not bad after all. I got good results even when it was just my first semester. Because I have more time to study [laughed]... (Chinese Student 1)

It was noted that challenges associated with adjustment were most intense upon arrival, yet positive outcomes were also reported as the end-product of the adjustment journey (Brown \& Holloway, 2008).

In addition, some participants also believed they have grown and become more mature effectively due to the positive changes in their perceptions during the adjustment. For this one Indian student, he shared his initial challenge was about dealing with his fear of failure. He identified those fears as the first thing he needed to counter to move forward in his adjustment process. He remarked, "I had a lot of this fear of failure...one thing I remembered is I told myself that I should not have this fear of failure. It stops you from focusing. You just don't worry about the result, you just do your best, and the best thing will happen" (Indian Student 1). Similarly, one Chinese student shared how she used to be afraid of many things when she first moved to the U.S. She realized this fear deterred her in her adjustment process, so she tried to grow out of that fear. She explained,

I tell myself if you're not afraid of anything, you can do it, so I just want to like this, destroy your fear and to do anything you want to do. Yes, even now, maybe sometimes I feel not very good, some problem in my life but I know I can do it, I can just to, I'm not very afraid of things anymore. (Chinese Student 1)

One student summed up her growth holistically, noting how "I feel more positive... I feel like I can accomplish more challenging things because I went through many things [during my adjustment]. So I felt more confident being here and live here..." (Chinese Student 2). For these participants, what started as disoriented feelings eventually resulted in positive growth and newly transformed perspectives (Pederson, 1995). Research conducted by Hashim (2012) also suggests that affective adjustment may lead to psychological wellbeing.

Meanwhile, interpersonal growth was also reported as part of the observed change noted by the participants. This growth was associated with improvement in social interactions with others. Many of them reported a rise in their confidence in interacting with new people. One of them expressed, "I feel like I know how to interact with people..." (Korean Student 2). An Indian student also reported a similar reflection: 
I feel that I'm now more confident, and I think my soft skills have also improved. I'm not afraid of public talks [anymore], not as much as when I was in India, and I'm just, it's easy for me now to go and meet people and talk, you know. (Indian Student 2)

Some noticed a shift in their personality, as they became more outgoing than their previous self. A Chinese student explained the differences she noticed about herself:

I think that I'm much more, a little bit more aggressive [extrovert] than I was in China, I kind of want to know more people, to make more friends, when I'm in the class, if I don't know the student who sits beside me, I just talk to them but if I was in China, maybe I didn't, I don't want to do that, maybe yes, when I first came here, I didn't do that. (Chinese Student 2)

Another student felt her social skills were enhanced; she started to smile more at more strangers and easily became accustomed to making new friends, especially locals. "The more friends I have over here, I realized ohh, I know how to make friends now. It's not that hard actually [laughed]" (Japanese Student 1). This interpersonal growth can be associated with how these students overcame their social loneliness by establishing their social circle in the new country.
In addition, increased use of a second language in daily lives resulted in improved language competencies that are beneficial for these international students personally and academically. As Wolf and Phung (2019) pointed out, proficiency in writing and listening in English remains a challenge to international students in their studies. One Korean student shared, "Before I came here, I'm just nervous that my English is not so good. But actually, it wasn't that bad. I learned [English] better here. No choice [laughed]..." (Korean Student 2). Another Japanese student similarly noted,

Everywhere I go here, it's just English English. I only speak my native when I call my parents. A few months after, I started to talk to my teacher, sometimes also in the class, which had never happened before this. (Japanese Student 1)

Mastering the language is particularly emphasized in culture learning (Masgoret $\&$ Ward, 2006). By becoming more wellversed in the host language, the participants noticed how they gradually became more adaptable to their new cultural and social surroundings.

As a whole, what started as adjustment difficulties was later perceived as a learning process that is complex and multifaceted. As noted by Garcia et al. (2020, p. 278), "the acculturation construct might benefit from a greater emphasis on its developmental dynamics." As the participants learned how to adjust to their new surroundings comfortably, the process was inevitably 
shaped into a rewarding learning process. It is evidenced that the adjustment process has significantly provided important learning experiences to the participants, resulting in their growth from various aspects, from academic to improved social skills.

\section{DISCUSSION}

In essence, this study unveiled three key findings of the adjustment process from the international graduate students' experiences. First, on the mosaic nature of their adjustment experiences, encompassing both psychological and sociocultural experiences. Secondly, the findings discussed the multiple adjustment strategies these international graduate students used, including shifting to positive mindsets, concentrating on academicrelated matters, and establishing key social supports. Finally, the third findings focused on the international graduate students experienced due to their adjustment. These three emerging themes can be mapped to the AIM framework for juxtaposing the acculturation process against the narratives of these international graduate students.

Overall, the findings imply a dynamic nature of the adjustment process, bounded on a process that aims to change oneself to fit the environment and offers opportunities for new learning and growth (Kim, 2001). When asked to describe their adjustment experiences, each participant highlighted many different events that they deemed important and memorable. All of the narratives exhibited in the findings are not characterized by rigidly fixed uniformity; instead, they vary in degrees across individuals. During the interviews, participants constantly reported on their engagement with their new cultural context. They reflected their personal stories and connected them to their learning growth all integrated into their adjustment journey. Their responses are consistent with what Kim posits as a life-changing journey, a process of becoming through personal reinvention, transformation, growth, and reaching out beyond the boundaries of one's existence. Their chosen acculturation strategy is what Berry (1997) describes as integration, where there is an interest in maintaining one's original culture and maintaining frequent interactions with the host culture. It is also evidenced that the interplay of psychological, instrumental, contextual, and developmental influences reflected the variations of the adjustment experiences reported by these students. Chen and Ross (2015, p. 177) noted that "there is not one way for students to engage in life and learning," including those life experiences they faced when adjusting during the interculturation process.

Participants in this study also indicated that their adjustment process was primarily geared towards finding fit as a competent graduate student. Their adjustment experiences, coping strategies, and changes were often associated with their identity and academic capabilities to function effectively as graduate students. Because the cost to study internationally is relatively more expensive than pursuing a local education in their home country, 
international students fly abroad with high expectations and expect to be academically successful by their sponsoring parties, including family members. Most of the participants were also high-achievers in their home countries. Thus, this brought superior expectations on themselves as well. For them, successfully adapting as a graduate student became the utmost important aspect in their adjustment because achieving academic goals is their primary intention of being in the U.S. To them, academic success as an international student yields personal well-being as a whole. As unveiled by Lin and Scherz (2014), the coping strategies employed by international graduate students during adjustment are primarily geared towards instructional and academic strategies while integrating linguistical and cultural strategies to ensure their successful academic experiences.

Kim (2001) posits that cross-cultural adjustment produces problems and growth for all individuals experiencing the process. Thus, the process is perceived as a doubleedged process, one that is simultaneously challenging yet enriching. The findings showed how participants viewed the adjustment process from a learning lens, making them very resilient despite dealing with various personal challenges. According to a study conducted by Wang (2009), positive selves and being in focus are the personality variables that are significantly associated with resiliency. In addition, they displayed a willingness to learn and made efforts to gain insights into how culturally different people live by examining their different values and practices (Hess, 1994). Hess also refers to this as cultural learning. Ideally, the process of cultural learning points toward developing intercultural competence. In a broad definition, intercultural competence encompasses a behavior of understanding, developing relationships, satisfaction, effectiveness, appropriateness, and adaptation to function in a differing culture other than oneself (Spitzberg \& Changnon, 2009).

\section{IMPLICATIONS AND RECOMMENDATIONS}

A key implication of this study is unveiling the strong emphasis of academic success as a key indicator of a successful adjustment process as viewed by these international graduate students. For these international graduate students, their cultural identity is shaped by who they are socioculturally and their identity as graduate students with academic responsibilities and expectations to succeed. Therefore, recommendations to support their adjustment process should include providing assistance that is not only focused on providing physical supports (such as airport transportation and temporary housing upon the first arrival) but also on organizing social events and academics related supports to help them adjust successfully in their studies and academic well-being. In addition, because the international graduate students' adjustment primarily revolves around their academic environment, creating a supportive culture among faculty and other students on campus is also important 
to highlight the diversity and differences that these international students bring on campus.

Furthermore, orientation or transition programs for international students can be approached from the perspective of transformative learning. Transformative learning is essentially a learning process of making meaning of one's experience (Mezirow, 1991). A beginning of transformative learning often starts with a "disorienting dilemma," which triggers a significant life event such as migrating to a new country. Upon inciting critical reflection of the whole process, new international students can be presented with a prospect of growth, learning, and a change in perspective resulting from the entire journey.

\section{CONCLUSIONS}

The adjustment process is very crucial for international students. It is a compulsory stage that they have to go through once they have decided to migrate to a new country to pursue their education. It is a complex process by itself, with many factors that make the process challenging (Berry, 1997; Searle \& Ward, 1990). However, at the same time, many factors are malleable towards a better, more manageable adjustment process that can be examined from psychological, instrumental, contextual, and developmental aspects as a whole. This study highlights all of the important experiences and strategies that are deemed significant in the process, and the growth associated with the adjustment experiences of the international graduate students.

\section{ACKNOWLEDGEMENT}

The author would like to thank all her research participants who willingly participated in her study, which made the writing of this paper possible.

\section{REFERENCES}

Adler, P. (1975). The transitional experience: An alternative view of culture shock. Journal of Humanistic Psychology, 15(3), 13-23.

Ahrari, S., Krauss, S. E., Suandi, T., Abdullah, H., Sahimi, A. H. A., Olutokunbo, A. S., \& Dahalan, D. (2019). A stranger in a strange land: Experiences of adjustment among international postgraduate students in Malaysia. Issues in Educational Research, 29(3), 611-632.

Andrade, M. S. (2006). International students in English-speaking universities: Adjustment factors. Journal of Research in International Education, 5(2), 131-154. https://doi. org/10.1177/1475240906065589

Berry, J. W. (1990). Psychology acculturation. In R. W. Brislin (Ed.), Applied cross-cultural psychology (pp. 232-253). Sage.

Berry, J. W. (1992). Acculturation and adaptation in a new society. International Migration, 30(1), 69-85.

Berry, J. W. (1997). Immigration, acculturation and adaptation. Applied Psychology: An International Review, 46(1), 5-34.

Birman, D. (1994). Acculturation and human diversity in a multicultural society. In E. J. Trickett, R. J. Watts, \& D. Birman (Eds.), Human diversity: Perspectives on people in context (pp. 261-284). Jossey-Bass Publishers. 
Bocher, S. (2006). Sojourners. In D. L. Sam \& J. W. Berry (Eds.), The Cambridge handbook of acculturation psychology (pp. 181-197). Cambridge University Press.

Brown, L., \& Holloway, I. (2008). The adjustment journey of international postgraduate students at an English university: An ethnographic study. Journal of Research in International Education, 7(2), 232-249. https://doi. org/10.1177/1475240908091306

Bui, T. A. (2021). Becoming an intercultural doctoral student: Negotiating cultural dichotomies. Journal of International Students, 11(1), 257265. https://doi.org/10.32674/jis.v11i1.1272

Chen, Y., \& Ross, H. (2015). Creating a home away from home: Chinese undergraduate student enclaves in US higher Education. Journal of Current Chinese Affairs, 44, 155-181.

Clandinin, D. J., \& Connelly, F. M. (2000). Narrative inquiry: Experience and story in qualitative research. Jossey-Bass.

Clark-Ibanez, M. (2004). Framing the social world with photo-elicitation interviews. American Behavioral Scientist, 47(12), 1507-1527. http:// dx.doi.org/10.1177/0002764204266236

Connelly, F. M., \& Clandinin, D. J. (1990). Stories of experience and narrative inquiry. Educational Researcher, 19(5), 2-14. https://doi. org/10.3102/0013189X019005002

Denzin, N., \& Lincoln, Y. (Eds.). (1994). Handbook of qualitative research. Sage.

Faiz, N. S. M., Awang, H., \& Maziana, M. (2017). Narrowing communication gaps in teaching international students. Pertanika Journal of Social Science and Humanities, 25(S), 215-222.

Garcia, J. G., DiNardo, J., Nuñez, M. I. L., Emmanuel, D., \& Chan, C. D. (2020). The integrated acculturation model: Expanding acculturation to cultural identities in addition to race and ethnicity. Journal of Multicultural Counselling and Development, 48(4), 271-287. https://doi. org/10.1002/jmcd.12199

Gardner, S. K. (2008). "What's too much and what's too little?": The process of becoming an independent researcher in doctoral education. The Journal of Higher Education, 79(3), 326350. https://doi.org/10.1353/jhe.0.0007

Hall, L. E. (2005). Dictionary of multicultural psychology: Issues, terms and concepts. Sage.

Harper, D. (2002). Talking about pictures: A case for photo elicitation. Visual Studies, 17(1), 13-26. https://doi.org/10.1080/14725860220137345

Harris, K. A. (2003). International students in cross-cultural transitions: A narrative inquiry [Doctoral dissertation, Rowan University]. ProQuest Dissertations and Theses database.

Hashim, H. A. (2012). Perceived barriers to recreation sport participation in university students: A comparison between international and local students in the United States. Pertanika Journal of Social Science and Humanities, 20(1), 197203.

Hess, J. D. (1994). The whole world guide to culture learning. Intercultural Press.

Hotta, J., \& Ting-Toomey, S. (2013). Intercultural adjustment and friendship dialectics in international students: A qualitative study. International Journal of Intercultural Relations, $37(5), 550-566$.

Institute of International Education. (2020). International students in the United States: 2020 fast facts. Open Doors. https://opendoorsdata. org/fast_facts/fast-facts-2020/

Kim, Y. Y. (2001). Becoming intercultural: An integrative theory of communication and crosscultural adaptation. Sage.

Kingston, E., \& Forland, H. (2008). Bridging the gap in expectations between international students 
and academic staff. Journal of Studies in International Education, 12(2), 204-221. https:// doi.org/10.1177/1028315307307654

Lin, S.-Y., \& Scherz, S. D. (2014). Challenges facing Asian international graduate students in the US: Pedagogical considerations in higher education. Journal of International Students, 4(1), 16-33.

Lovitts, B. E. (2005). Being a good course-taker is not enough: A theoretical perspective on the transition to independent research. Studies in Higher Education, 30(2), 137-154. https://doi. org/10.1080/03075070500043093

Masgoret, A., \& Ward, C. (2006). Culture learning approach to acculturation. In D. L. Sam \& J. W. Berry (Eds.), The Cambridge handbook of acculturation psychology (pp. 58-77), Cambridge University Press.

Mazzarol, T., \& Soutar, G. N. (2002). "Pushpull" factors influencing international student destination choice. The International Journal of Educational Management, 16(2), 82-90. https:// doi.org/10.1108/09513540210418403

Merriam, S. B. (2009). Qualitative research: A guide to design and implementation. Jossey-Bass.

Mezirow, J. (1991). Transformative dimensions of adult learning. Jossey-Bass.

Miles, M. B., \& Huberman, A. M. (1994). Qualitative data analysis: A sourcebook of new methods (2nd ed.). Sage.

NAFSA. (2020). The United States of America: Benefits from International Students. https:// www.nafsa.org/sites/default/files/media/ document/isev-2020.pdf

Patton, M. Q. (2002). Qualitative research and evaluation methods. Sage.

Pederson, P. (1995). The five stages of culture shock. Greenword Press.

Polkinghorne, D. E. (1995). Narrative configuration in qualitative analysis. In J. A. Hatch \& R,
Wisniewski (Eds.), Life history and narrative (pp. 5-21). The Falmer Press.

Sam, D. L. (2006). Acculturation: Conceptual background and core components. In D. L. Sam \& J. W. Berry (Eds.), The Cambridge handbook of acculturation psychology (pp. 1126), Cambridge University Press.

Sawir, E., Marginson, S., Deumert, A., Nyland, C., \& Ramia, G. (2008). Loneliness and international students: An Australian study. Journal of Studies in International Education, 12(2), 148-180. https://doi.org/10.1177/1028315307299699

Searle, W., \& Ward, C. (1990). The prediction of psychological and sociocultural adjustment during cross-cultural transitions. International Journal of Intercultural Relations, 14(4), 449-464. https://doi.org/10.1016/01471767(90)90030-Z

Schwandt, T.A. (2007). The SAGE dictionary of qualitative inquiry (3rd ed.). Sage.

Spitzberg, B. H., \& Changnon, G. (2009). Conceptualizing intercultural competence. In D. K. Deardorff (Ed.), The SAGE handbook of intercultural competence (pp. 2-52). Sage.

Trice, A. G., \& Yoo, J. E. (2007). International graduate students' perceptions of their academic experience. Journal of Research in International Education, 6(1), 41-66. https://doi. org/10.1177/1475240907074788

Wang, J. (2009). A study of resiliency characteristics in the adjustment of international graduate students at American universities. Journal of Studies in International Education, 13(1), 2245. https://doi.org/10.1177/1028315307308139

Wolf, D. M., \& Phung, L. (2019). Studying in the United States: Language learning challenges, strategies, and support services. Journal of International Students, 9(1), 211-224. 